15

\title{
Оперативный контроль коэффициента диффуззии в тонких анизотропных пористых материалах
}

\author{
(ㄱ В.П. Беляев, С.В. Мищенко, П.С. Беляев \\ Тамбовский государственный технический университет, Тамбов, Россия \\ T E-mail: bps800@yandex.ru
}

Поступило в Редакцию 3 сентября 2018 г.

Представлен метод неразрушающего контроля коэффициента диффузии растворителей в тонких волокнистых материалах с существенной анизотропией свойств. Определение искомого коэффициента обеспечивается при отсутствии реальной статической характеристики применяемого преобразователя концентрации диффузанта в твердой фазе, что существенно повышает производительность контроля.

DOI: 10.21883/PJTF.2019.01.47153.17513

В разных областях промышленности все более широкое применение получают пористые волокнистые композиционные материалы, использующиеся в виде тонколистовых изделий, получение и эксплуатация которых часто связаны с диффузией различных веществ $[1,2]$. В частности, средства химической регенерации воздуха систем жизнеобеспечения изготавливаются с использованием тканых и нетканых материалов или на бумажной основе путем распределения в матрице сорбционноактивных материалов [3]. Для повышения производительности исследований в направлении создания новых листовых сорбентов необходимо обеспечить оперативный контроль коэффициента диффузии в полупродуктах и изделиях с учетом вероятной анизотропии свойств.

Применяемая в настоящее время аппаратура для измерения коэффициента диффузии отличается достаточной сложностью $[4,5]$, значительными массогабаритными параметрами и высокой стоимостью [4-6]. Кроме того, часто возникает необходимость защиты персонала от излучений $[5,6]$. Перспективным направлением в плане повышения производительности подобных исследований является разработка импульсных методов неразрушающего контроля (НК), характеризующихся малой длительностью процессов измерений и широко использующихся для определения теплофизических характеристик $[7,8]$. Задача достижения сопоставимой производительности при разработке аналогичных методов НК для измерения характеристик массопереноса осложнена необходимостью проведения длительной предварительной операции градуировки применяемых датчиков концентрации диффузанта по каждой системе композит-диффундирующее вещество [4-6,9,10]. А измерение локальной концентрации диффундирующих веществ, лежащее в основе реализации методов НК, представляет собой достаточно сложную задачу по сравнению с измерением локальных значений температуры $[5,6,11]$.

Цель нашего исследования - разработка метода измерения коэффициента диффузии растворителей в изделиях из тонких пористых материалов, обеспечиваю- щего оперативный контроль искомой характеристики в различных направлениях анизотропного материала без разрушения контролируемых изделий.

Существо предлагаемого метода рассмотрим на примере определения коэффициента диффузии влаги в бумаге из целлюлозы, обладающей анизотропией свойств в машинном и поперечном направлениях. Фрагмент листового пористого материала толщиной $h \mathrm{c}$ равномерным начальным распределением растворителя (влаги) помещается на плоскую подложку из не смачиваемого водой материала, например фторопласта. К поверхности образца плоской прямоугольной поверхностью прижимается измерительный зонд, имеющий вдоль оси симметрии прямолинейный паз длиной $L$ для временного размещения линейного импульсного источника влаги. По обе стороны паза на одинаковом расстоянии $x_{0} \geq 10 \mathrm{~h}$ от его оси расположены электроды гальванического преобразователя (ГП) в виде прямолинейных отрезков длиной $l$. ГП выбран в качестве датчика концентрации распределенных в твердой фазе растворителей ввиду его высокой чувствительности, малой инерционности и способности обеспечивать более высокую локальность контроля по сравнению с другими известными электрофизическими преобразователями $[10,12]$. Необходимо, чтобы длина паза $L$ имела размер не менее $20\left(x_{0}+l\right)$, а размеры плоскости подлежащего контролю изделия должны быть достаточными для размещения измерительного зонда.

Путем равномерного перемещения по пазу зонда вращающегося увлажняющего диска, соединенного с дозирующим устройством, наносится импульс дозой влаги в виде увлажненной линии. После подачи линейного импульса источник влаги удаляется из зонда, прямолинейный паз герметизируется заглушкой, а сам зонд обеспечивает гидроизоляцию поверхности образца в зоне действия источника и прилегающей к ней области контроля распространения влаги. После подачи импульса влаги фиксируется изменение электродвижущей силы (ЭДС) гальванического преобразователя во времени. 
При описанной постановке эксперимента и определяющих размерах контролируемого изделия и измерительного устройства массоперенос в тонколистовом материале аналогичен распространению влаги в неограниченной среде при нанесении импульсного воздействия от плоского источника массы. При этом процесс распространения влаги может описываться краевой задачей [8]:

$$
\begin{gathered}
\frac{\partial U(x, \tau)}{\partial \tau}=\frac{\partial}{\partial x}\left[D \frac{\partial U(x, \tau)}{\partial x}\right]+\frac{W}{\rho_{0}} \delta(x, \tau), \\
\tau>0, \quad 0 \leq x<\infty, \\
U(x, 0)=U_{0}, \quad \frac{\partial U(0, x)}{\partial x}=0, \quad U(\infty, \tau)=U_{0},
\end{gathered}
$$

где $U(x, \tau)$ - концентрация влаги в исследуемом изделии на расстоянии $x$ от линейного источника импульса массы в момент времени $\tau$; $D$ - коэффициент диффузии; $\delta(x, \tau)-\delta$-функция Дирака; $\rho_{0}-$ плотность абсолютно сухого исследуемого материала; $W$ мощность „мгновенного“ источника влаги, подействовавшего в начале координат $x=0$, вычисляемая как отношение количества влаги (подведенной к контролируемому изделию) к произведению длины линии $L$ импульсного воздействия на толщину $h$ исследуемого листового материала; $U_{0}-$ начальное влагосодержание в исследуемом материале.

В этом случае изменение концентрации растворителя в зоне действия источника описывается функцией [8]:

$$
U(x, \tau)-U_{0}=W /\left(\rho_{0} \sqrt{4 \pi D \tau} \exp \left[x^{2} / 4 D \tau\right]\right),
$$

а коэффициент диффузии определяется соотношением

$$
D=x_{0}^{2} /\left(2 \tau_{\max }\right),
$$

где $\tau_{\max }$ - время, соответствующее максимуму на кривой изменения концентрации $U\left(x_{0}, \tau\right)$ на расстоянии $x_{0}$ от линейного источника.

После импульсного воздействия на заданном расстоянии $x_{0}$ от линейного источника наблюдается изменение концентрации в виде характерных кривых, имеющих восходящую ветвь от начала импульсного воздействия до момента $\tau_{\max }$ и нисходящую ветвь, наблюдаемую после наступления момента $\tau_{\max }$. Известно [12], что статическая характеристика ГП монотонна и имеет три участка. Наиболее предпочтительным для использования является средний участок со стабильным сигналом в диапазоне приблизительно $(0.7-0.9) E_{e}$ и высокой чувствительностью к изменению концентрации растворителя (влаги). Здесь $E_{e}$ - максимальный сигнал ГП, соответствующий переходу растворителя из области связанного состояния с твердой фазой исследуемого материала в область свободного состояния. Выберем два одинаковых значения ЭДС $E^{*}\left(x_{0}, \tau_{1}\right)$ и $E^{*}\left(x_{0}, \tau_{2}\right)$ из среднего участка статической характеристики ГП, достигаемых в моменты времени $\tau_{1}$ и $\tau_{2}$ соответственно на восходящей и нисходящей ветвях кривой изменения ЭДС во
Таблица 1. Коэффициент диффузии влаги в машинном направлении бумаги

\begin{tabular}{c|r|c|c}
\hline$\tau_{1 i}, \mathrm{~s}$ & \multicolumn{1}{|c|}{$\tau_{2 i}, \mathrm{~s}$} & $D_{i} \cdot 10^{8}, \mathrm{~m}^{2} / \mathrm{s}$ & $\Delta D_{i} \cdot 10^{9}, \mathrm{~m}^{2} / \mathrm{s}$ \\
\hline 179.6 & 902.8 & 2.21 & 3.38 \\
245.8 & 1276.5 & 1.59 & -2.76 \\
182.1 & 911.8 & 2.18 & 3.11 \\
186.3 & 822.7 & 2.24 & 3.65 \\
298.4 & 1215.4 & 1.44 & -4.31 \\
265.5 & 1197.6 & 1.56 & -3.15 \\
188.5 & 685.3 & 2.38 & 5.12 \\
292.9 & 1299.4 & 1.42 & -4.51 \\
297.4 & 1212.6 & 1.46 & -4.27 \\
145.9 & 1035.6 & 2.40 & 5.32
\end{tabular}

Примечание. $i=1,2, \ldots, 10-$ порядковый номер опыта; математическое ожидание $\bar{D}=1.8 \cdot 10^{-8} \mathrm{~m}^{2} / \mathrm{s}$; относительная погрешность результата измерения $\delta D=9 \%$.

времени. Соответствующие им одинаковые (вследствие монотонности статической характеристики) значения концентрации $U^{*}\left(x_{0}, \tau_{1}\right)$ и $U^{*}\left(x_{0}, \tau_{2}\right)$, достигаемые в моменты времени $\tau_{1}$ и $\tau_{2}$, могут быть определены исходя из выражения (1) с учетом (2)

$$
\begin{aligned}
& U^{*}\left(x_{0}, \tau_{1}\right)=W / 2 \rho_{0}\left[\left(\pi D \tau_{1}\right) \exp \left(\tau_{\max } / \tau_{1}\right)\right]^{-1 / 2}, \\
& U^{*}\left(x_{0}, \tau_{2}\right)=W / 2 \rho_{0}\left[\left(\pi D \tau_{2}\right) \exp \left(\tau_{\max } / \tau_{2}\right)\right]^{-1 / 2} .
\end{aligned}
$$

Деление (3) на (4) приводит к следующему выражению:

$$
\sqrt{\tau_{2} / \tau_{1}} \exp \left[0.5\left(\tau_{\max } / \tau_{2}-\tau_{\max } / \tau_{1}\right)\right]=1 .
$$

Из (5) с учетом (2) получено расчетное выражение для определения искомого коэффициента диффузии

$$
D=x_{0}^{2}\left(\tau_{2}-\tau_{1}\right) /\left[4 \tau_{2} \tau_{1} \ln \sqrt{\left(\tau_{2} / \tau_{1}\right)}\right] .
$$

Для обеспечения контроля коэффициента диффузии в различных направлениях анизотропного материала линию импульсного воздействия ориентируют в заданном направлении материала (например, при исследовании бумаги - в машинном или поперечном направлении). При этом обеспечивается однонаправленный массоперенос в нужном направлении, не искаженный массопереносом в направлении, перпендикулярном исследуемому. За счет этого повышаются точность контроля и возможность определения искомого коэффициента в различных направлениях анизотропного листового материала.

В табл. 1 и 2 представлены фрагменты результатов 20кратных измерений коэффициента диффузии влаги в машинном и поперечном направлениях бумаги толщиной $0.14 \mathrm{~mm}$, плотностью в сухом состоянии $2.2 \cdot 10^{2} \mathrm{~kg} / \mathrm{m}^{3}$ (по десять результатов для каждого направления). Расстояние от источника дозы растворителя до расположения электродов ГП составляет $4 \mathrm{~mm}$. Прижимаемая к исследуемому изделию плоская поверхность зонда 
Таблица 2. Коэффициент диффузии влаги в поперечном направлении бумаги

\begin{tabular}{c|c|c|c}
\hline$\tau_{1 i}, \mathrm{~s}$ & $\tau_{2 i} \cdot 10^{3}, \mathrm{~s}$ & $D_{i} \cdot 10^{9}, \mathrm{~m}^{2} / \mathrm{s}$ & $\Delta D_{i} \cdot 10^{9}, \mathrm{~m}^{2} / \mathrm{s}$ \\
\hline 612.3 & 2.317 & 7.22 & -0.96 \\
768.1 & 2.052 & 6.63 & -1.55 \\
583.3 & 1.551 & 8.75 & 0.57 \\
451.4 & 1.351 & 10.77 & 2.58 \\
832.6 & 2.229 & 6.11 & -2.07 \\
496.2 & 1.417 & 9.98 & 1.80 \\
506.5 & 1.463 & 9.74 & 1.55 \\
790.7 & 2.151 & 6.39 & -1.79 \\
848.9 & 2.320 & 5.94 & -2.24 \\
722.6 & 2.009 & 6.93 & -1.25
\end{tabular}

Пр и ме ч ан ие. $i=1,2, \ldots, 10-$ порядковый номер опыта; математическое ожидание $\bar{D}=8.2 \cdot 10^{-9} \mathrm{~m}^{2} / \mathrm{s}$; относительная погрешность результата измерения $\delta D=10 \%$.

имеет размеры $120 \times 100 \mathrm{~mm}$, длина паза для размещения источника $-90 \mathrm{~mm}$. Диаметр электродов гальванического преобразователя $0.2 \mathrm{~mm}$, длина около $5 \mathrm{~mm}$. Величина вносимой при импульсе влаги порядка 4-6 $\mu \mathrm{g}$. Длительность эксперимента не выше $40 \mathrm{~min}$.

В настоящее время нет возможности оценить систематическую составляющую погрешности в связи с отсутствием эталонных материалов для рассматриваемого класса систем пористый материал-растворитель, поэтому авторами представлена оценка случайной составляющей погрешности. Относительная погрешность результата измерения определялась следующим образом:

$$
\delta_{\Sigma}=t_{\alpha, n} S_{n} /(\bar{D} \sqrt{n})
$$

где $\bar{D}$ - математическое ожидание случайной величины; $t_{\alpha, n}-$ коэффициент Стьюдента при доверительной вероятности $\alpha$ и количестве измерений $n$;

$$
S_{n}=\sqrt{\sum_{i=1}^{n}\left(D_{i}-\bar{D}\right)^{2} /(n-1)}
$$

- среднеквадратическая погрешность отдельного измерения; $\Delta D=D_{i}-\bar{D}$.

Таким образом, для определения коэффициента диффузии необходимо выбрать два произвольных одинаковых значения на восходящей и нисходящей ветвях кривой изменения ЭДС во времени, определить значения моментов времени, в которые они достигаются, и рассчитать величину искомой характеристики массопереноса. Повышение производительности по сравнению с известными методами обеспечивается за счет меньшей длительности эксперимента, исключения операции по изготовлению специальных образцов для исследований и наиболее длительной операции градуировки датчиков концентрации распределенных в пористой среде растворителей.

\section{Список литературы}

[1] Каблов Е.Н. // Авиационные материалы и технологии. 2015. № 1(34). С. 3-33.

[2] Гаршин А.П., Кулик В.И., Матвеев С.А., Нилов А.С. // Новые огнеупоры. 2017. № 4. C. 20-35. DOI: $10.17073 / 1683-$ 4518-2017-4-20-35

[3] Карелин А.И., Гладышев Н.Ф., Гладымева Т.В. // ЖНХ. 2014. T. 59. № 4. С. 517-525. DOI: $10.7868 / \mathrm{S} 0044457 \mathrm{X} 14040060$

[4] Коптюг И.В., Сагдеев Р.3. // Успехи химии. 2002. Т. 71. № 10. C. 899-949.

[5] Nizovtsev M.I., Stankus S.V., Sterlyagov A.N., Terekhov V.I., Khairulin R.A. // Int. J. Heat Mass Transfer. 2008. V. 51. N 17. P. 4161-4167. https://doi.org/10.1016/j.ijheatmasstransfer.2008.01.013

[6] Roels S., Carmeliet J. // Int. J. Heat Mass Transfer. 2006. V. 49. N 25. P. 4762-4772. https://doi.org/10.1016/j.ijheatmasstransfer.2006.06.035

[7] Селиванова 3.М., Хоан Т.A. // Измерительная техника. 2017. № 5. C. 44-48.

[8] Пономарев С.В., Буланова В.О., Дивин А.Г., Буланов Е.В. // Метрология. 2015. № 4. С. 40-50.

[9] Maksimović M., Stojanović G.M., Radovanović M., Malešev M., Radonjanin V., Radosavljević G., Smetana W. // Construct. Building Mater. 2012. V. 26. N 1. P. 327-333. https://doi.org/10.1016/j.conbuildmat.2011.06.029

[10] Улыбин А.В., Старцев С.А., Зубков С.В. // Инж.-строит. журн. 2013. № 7. C. 32-39. DOI: 10.5862/MCE.42.5

[11] Котерева Т.В., Иконников В.Б., Гавришук Е.М., Потапов А.М., Савин Д.В. // ЖТФ. 2018. Т. 88. В. 7. С. 1110 1115. DOI: 10.21883/PJTF.2018.07.46189.2572

[12] Беляев В.П., Мищенко С.В., Беляев П.С. // Инж.-физ. журн. 2017. Т. 90. № 3. С. 733-741. 